Retrospective Audit

\title{
e Radiofrequency Neurotomy for Treatment of Low Back Pain in Patients with Minor Degenerative Spondylolisthesis
}

\author{
Stephan Klessinger, MD
}

From: Nova Clinic, Biberach Baden-Württemberg, Germany

Address correspondence: Dr. med. Stephan Klessinger Facharzt für Neurochirurgie Nova Clinic Eichendorffweg 5 88400 Biberach Baden-Württemberg, German E-mail:

klessinger@nova-clinic.de

Disclaimer: Previous presentations: An abstract based on this data was presented as poster at the 27th annual meeting of the American Academy of Pain Medicine, March 2011, Washington and as ora presentation at the 19th annual scientific meeting of the International Spine Intervention Society, August 2011, Chicago.

Conflict of interest: None.

Manuscript received: 10/23/2011

Revised manuscript received: $11 / 21 / 2011$

Accepted for publication: 12/01/2011

Free full manuscript: www.painphysicianjournal.com

Background: Degenerative spondylolisthesis is one of the major causes for low back pain. Morphological abnormalities of the zygapophysial joints are a predisposing factor in the development of degenerative spondylolisthesis. Therefore, radiofrequency neurotomy seems to be a rational therapy.

Objectives: To determine if radiofrequency neurotomy is effective for patients with low back pain and degenerative spondylolisthesis.

Study design: Retrospective practice audit

Setting: Single spine center

Methods: Charts of all patients with degenerative spondylolisthesis who underwent treatment with radiofrequency neurotomy during a time period of 3 years were reviewed. Only patients with magnetic resonance imaging confirming the diagnosis were included. Patients with a lumbar spine operation in their history, patients with neurological deficits, and patients with a follow-up less than 3 months were excluded. Patients were treated with lumbar radiofrequency neurotomy. Positive treatment response was defined as at least a $50 \%$ reduction in pain. A radiofrequency neurotomy was only performed after positive diagnostic medial branch blocks.

Results: During a time period of 3 years, 1,490 patients were treated with lumbar radiofrequency neurotomy. Forty of these patients with degenerative spondylolisthesis were included. A significant pain reduction was achieved in $65 \%$ of the patients.

Limitations: This audit is retrospective and observational, and therefore does not represent a high level of evidence. However, to our knowledge, since this information has not been previously reported and no specific nonoperative treatment for lumbar pain in patients with degenerative spondylolisthesis exists, it appears to be the best available research upon which to recommend treatment and to plan higher quality studies.

Conclusions: Zygapophysial joints are a possible source of pain in patients with spondylolisthesis. Radiofrequency neurotomy is a rational, specific nonoperative therapy in addition to other nonoperative therapy methods with a success rate of $65 \%$. This is the first study to determine the effect of radiofrequency neurotomy in patients with minor degenerative spondylolisthesis.

Key words: degenerative spondylolisthesis, zygapophysial joints, facet joints, radiofrequency neurotomy, medial branch, pain therapy, back pain

Pain Physician 2012; 15:-E71-E78

n degenerative spondylolisthesis, the whole upper vertebra (the vertebral body and posterior part of the vertebra including the neural arch and processes) slips relative to the lower vertebra (1) due to degenerative changes in the spine.
The etiology of degenerative spondylolisthesis is multifactorial, and is interlinked with other pathologies, such as, for example, disc degeneration, zygapophysial joint osteoarthritis and spinal stenosis $(1,2)$. The major reasons that probably lead to the develop- 
ment of degenerative vertebral slippage are: arthritis of the zygapophysial joints with loss of their normal structural support; malfunction of the ligamentous stabilizing component, probably due to hyperlaxity; and ineffectual muscular stabilization $(1,2)$. It seems to be evident that morphological abnormalities of the zygapophysial joints in the lumbar spine are a significant cause of low back pain and segmental instability, and a predisposing factor in the development of degenerative spondylolisthesis $(3,4)$.

Patients presenting with degenerative spondylolisthesis have any combination of low back pain, neurogenic claudication, vesicorectal disorder, and radiculopathy (5). The most common complaint of patients with degenerative spondylolisthesis is back pain.

Conservative treatment should be the initial course of action in most cases of degenerative spondylolisthesis, with or without neurologic symptoms $(1,5)$. Treatment options include the use of analgesics and nonsteroidal anti-inflammatory drugs (NSAIDs) to control pain; epidural steroid injections; and physical methods such as bracing and exercises $(1,5,6)$. Only $15 \%$ of patients with degenerative spondylolisthesis are surgical candidates (6). There are a number of publications about the surgical treatment of signs related to degenerative spondylolisthesis, including the recent comprehensive review by Sengupta and Herkowitz (2).

To find a specific treatment option, it is important to define the source of pain. Degenerative spondylolisthesis is one of the major causes for low back pain. The most probable sources for low back pain are the degenerated zygapophysial joints, together with segmental instability, causing tension on the joint capsule (1). Capsular distension results in local and referred pain (7). Therefore, the idea is obvious to apply methods of specific zygapophysial joint therapy to patients with degenerative spondylolisthesis.

The literature provides limited information regarding the treatment of zygapophysial joint pain, with only medial branch blocks and radiofrequency neurotomy showing evidence for effectively reducing pain (7-14). The rationale of radiofrequency neurotomy is to interrupt nociceptive pathways. A Teflon-coated electrode with an exposed tip is inserted onto the medial branch of the lumbar dorsal ramus. When a high-frequency electrical current is applied to the electrode, it concentrates around the exposed tip and coagulates the surrounding tissue, including the target nerve. Radiofrequency treatment is the "gold standard" for treating facetogenic pain (14).
The aim of this study was to find out if radiofrequency neurotomy is a rational treatment for low back pain due to degenerative spondylolisthesis. The results were analyzed for duration of pain relief; different levels and grade of spondylolisthesis; and for differences in age and sex.

\section{Methods}

An electronic medical record system was used to identify all patients in a single spine center with a diagnosis of degenerative spondylolisthesis who had received lumbar radiofrequency neurotomy during a 3 year period (from June 2006 until the end of May 2009). Most of the patients $(82.1 \%)$ were tested before the neurotomy with controlled medial branch blocks (15); the other patients only had single medial branch blocks before radiofrequency neurotomy. A radiofrequency neurotomy was only considered after positive testing (at least $80 \%$ pain relief). Injections were performed with fluoroscopic visualization using established techniques (15) using bupivacaine (0.25\%). The patients were assessed and treated in a suburban practice by 2 neurosurgeons with a vocational interest in not only the spine and musculoskeletal pain, but also operations of the spine. The pain therapy procedures were performed in an interventional pain management ambulatory surgery center by these 2 neurosurgeons. Only one of them performed the radiofrequency procedures. Patients came through referral by a physician or by their own initiative.

All patients presented with therapy-resistant pain despite medication and physical therapy. Included patients had magnetic resonance imaging (MRI) verifying the diagnosis of degenerative spondylolisthesis. The radiologist's written report confirmed our own report. Plain (standing) radiographs were not consistently available. Excluded were patients with a spondylolytic spondylolisthesis, patients with a history of lumbar spinal operation, and patients with neurological deficits. Also excluded were patients with a follow-up of less than 3 months (Fig. 1).

The response was evaluated. A treatment response was positive if at least a $50 \%$ reduction in pain was achieved. For every patient, the first follow-up examination was one month after the intervention. Further examinations were arranged according to reported concerns from the patients. The statistical analysis was performed using Chi-square-tests.

The level of spondylolisthesis was always included in the radiofrequency neurotomy. In nearly all patients, 


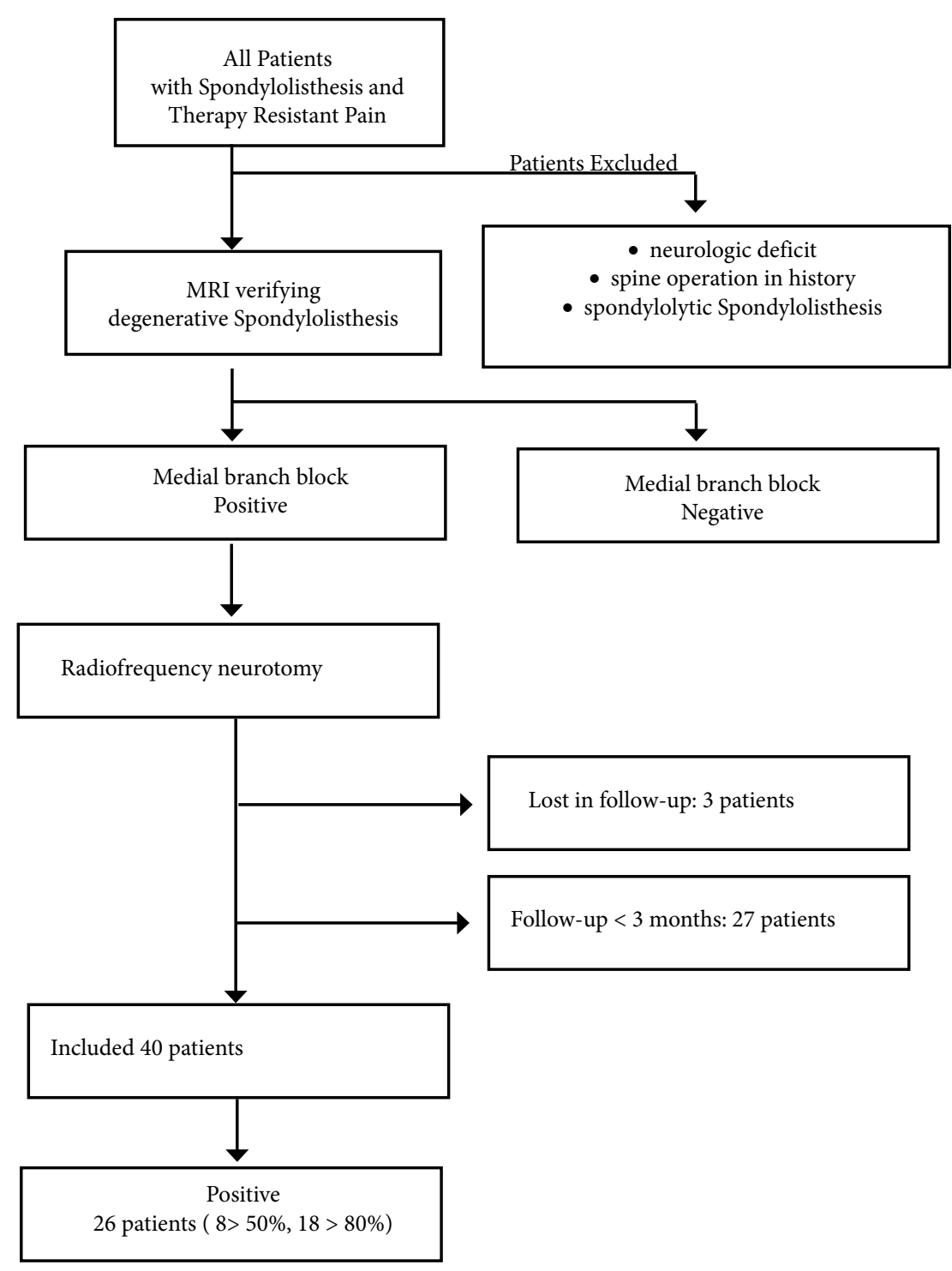

Fig. 1. Schematic presentation of patient flow.

one or 2 adjacent levels were also included (Table 1). Target joints were identified by the pain pattern, local tenderness over the area, and provocation of pain with deep pressure. For radiofrequency neurotomy a NeuroTherm JK3 generator (NeuroTherm, Wilmington, $\mathrm{MA}$ ) was used. The cannulae used were $150 \mathrm{~mm}$ length, 20 -gauge with a $10 \mathrm{~mm}$ active tip. The total time of the lesion at $80^{\circ} \mathrm{C}$ was 60 seconds for each cycle at each level. At each level, the needle was placed parallel to the nerve; multiple lesions were made in parallel for each medial branch. Each neurotomy was performed by one neurosurgeon with fluoroscopic visualization (Fig. 2) using established techniques $(8,16)$. In all cases, intravenous access was established. Lidocaine was used as a local anaesthetic. Nerve stimulation was not performed prior to radiofrequency lesioning.

\section{Results}

In a 3-year period, 1,490 radiofrequency neurotomy procedures were performed on the lumbar spine. 
Pain Physician: January/February 2012; 15:E71-E78

Table 1. Characteristics of the spondylolisthesis, radiofrequency neurotomy, pain relief and follow-up

\begin{tabular}{|c|c|c|c|c|c|c|c|}
\hline \multirow[b]{2}{*}{ Age } & \multirow[b]{2}{*}{ Gender } & \multicolumn{2}{|c|}{ Spondylolisthesis } & \multicolumn{2}{|c|}{ RF-neurotomy } & \multirow{2}{*}{$\begin{array}{l}\text { Relief } \\
\text { Month }\end{array}$} & \multirow[t]{2}{*}{ Follow-up } \\
\hline & & Level & Grade & Side & Level & & \\
\hline 41 & $\mathrm{~m}$ & $\mathrm{~L} 4 / 5$ & 1 & $\mathrm{R}$ & $\mathrm{L} 4 / 5 / \mathrm{S} 1$ & (1) & 46 \\
\hline 66 & $\mathrm{w}$ & $\mathrm{L} 5 / \mathrm{S} 1$ & 1 & $\mathrm{R}$ & $\mathrm{L} 4 / 5 / \mathrm{S} 1$ & 42 & 47 \\
\hline 60 & $\mathrm{~m}$ & $\mathrm{~L} 5 / \mathrm{S} 1$ & 1 & $\mathrm{~B}$ & $\mathrm{~L} 4 / 5 / \mathrm{S} 1$ & 5 & 38 \\
\hline 61 & $\mathrm{w}$ & $\mathrm{L} 5 / \mathrm{S} 1$ & 1 & B & $\mathrm{L} 4 / 5 / \mathrm{S} 1$ & 26 & 27 \\
\hline 67 & $\mathrm{~m}$ & L5/S1 & 1 & $\mathrm{~L}$ & $\mathrm{~L} 4 / 5 / \mathrm{S} 1$ & 34 & 48 \\
\hline 66 & $\mathrm{w}$ & $\mathrm{L} 5 / \mathrm{S} 1$ & 1 & B & $\mathrm{L} 3 / 4 / 5 / \mathrm{S} 1$ & - & 44 \\
\hline 63 & $\mathrm{w}$ & L5/S1 & 1 & $\mathrm{~B}$ & $\mathrm{~L} 4 / 5 / \mathrm{S} 1$ & - & 21 \\
\hline 64 & $\mathrm{w}$ & $\mathrm{L} 3 / 4$ & 1 & B & $\mathrm{L} 3 / 4 / 5$ & 6 & 15 \\
\hline 71 & $\mathrm{~m}$ & $\mathrm{~L} 3 / 4$ & 1 & $\mathrm{~B}$ & $\mathrm{~L} 3 / 4 / 5 / \mathrm{S} 1$ & 4 & 7 \\
\hline 60 & $\mathrm{w}$ & $\mathrm{L} 4 / 5$ & 1 & B & $\mathrm{L} 4 / 5 / \mathrm{S} 1$ & - & 36 \\
\hline 77 & $\mathrm{w}$ & $\mathrm{L} 4 / 5$ & 1 & B & $\mathrm{L} 3 / 4 / 5$ & 10 & 39 \\
\hline 65 & $\mathrm{w}$ & $\mathrm{L} 3 / 4$ & 1 & $\mathrm{~L}$ & $\mathrm{~L} 3 / 4 / 5$ & 4 & 8 \\
\hline 76 & $\mathrm{~m}$ & $\mathrm{~L} 4 / 5$ & 2 & B & $\mathrm{L} 4 / 5 / \mathrm{S} 1$ & - & 21 \\
\hline 80 & $\mathrm{~m}$ & L5/S1 & 1 & $\mathrm{R}$ & $\mathrm{L} 3 / 4 / 5 / \mathrm{S} 1$ & 7 & 11 \\
\hline 66 & $\mathrm{w}$ & $\mathrm{L} 4 / 5$ & 1 & $\mathrm{~L}$ & $\mathrm{~L} 4 / 5 / \mathrm{S} 1$ & - & 24 \\
\hline 73 & $\mathrm{w}$ & $\mathrm{L} 4 / 5$ & 1 & $\mathrm{R}$ & $\mathrm{L} 4 / 5 / \mathrm{S} 1$ & 6 & 36 \\
\hline 76 & $\mathrm{w}$ & $\mathrm{L} 4 / 5$ & 1 & $\mathrm{R}$ & $\mathrm{L} 3 / 4 / 5 / \mathrm{S} 1$ & 23 & 23 \\
\hline 68 & $\mathrm{w}$ & $\mathrm{L} 5 / \mathrm{S} 1$ & 2 & B & $\mathrm{L} 5 / \mathrm{S} 1$ & 3 & 3 \\
\hline 68 & $\mathrm{w}$ & L5/S1 & 2 & B & $\mathrm{L} 4 / 5$ & 3 & 3 \\
\hline 62 & $\mathrm{~m}$ & L5/S1 & 1 & $\mathrm{~B}$ & $\mathrm{~L} 4 / 5 / \mathrm{S} 1$ & 15 & 21 \\
\hline 64 & $\mathrm{w}$ & $\mathrm{L} 4 / 5$ & 1 & $\mathrm{~L}$ & $\mathrm{~L} 4 / 5 / \mathrm{S} 1$ & - & 23 \\
\hline 77 & $\mathrm{w}$ & $\mathrm{L} 3 / 4$ & 1 & $\mathrm{~L}$ & $\mathrm{~L} 3 / 4 / 5$ & 21 & 24 \\
\hline 68 & $\mathrm{w}$ & $\mathrm{L} 4 / 5$ & 1 & B & $\mathrm{L} 4 / 5 / \mathrm{S} 1$ & - & 3 \\
\hline 49 & $\mathrm{w}$ & $\mathrm{L} 4 / 5$ & 1 & $\mathrm{~L}$ & $\mathrm{~L} 4 / 5 / \mathrm{S} 1$ & 5 & 7 \\
\hline 67 & $\mathrm{w}$ & $\mathrm{L} 4 / 5$ & 1 & $\mathrm{~L}$ & $\mathrm{~L} 3 / 4 / 5 / \mathrm{S} 1$ & 4 & 6 \\
\hline 67 & $\mathrm{~m}$ & $\mathrm{~L} 4 / 5$ & 1 & $\mathrm{~L}$ & $\mathrm{~L} 4 / 5 / \mathrm{S} 1$ & - & 4 \\
\hline 59 & $\mathrm{~m}$ & $\mathrm{~L} 4 / 5$ & 1 & $\mathrm{~B}$ & $\mathrm{~L} 4 / 5 / \mathrm{S} 1$ & - & 23 \\
\hline 64 & $\mathrm{w}$ & L5/S1 & 1 & $\mathrm{R}$ & $\mathrm{L} 3 / 4 / 5 / \mathrm{S} 1$ & 5 & 18 \\
\hline 69 & $\mathrm{~m}$ & L5/S1 & 1 & $\mathrm{R}$ & $\mathrm{L} 4 / 5 / \mathrm{S} 1$ & 4 & 22 \\
\hline 54 & $\mathrm{w}$ & L5/S1 & 1 & $\mathrm{~B}$ & $\mathrm{~L} 4 / 5 / \mathrm{S} 1$ & (1) & 4 \\
\hline 70 & $\mathrm{~m}$ & $\mathrm{~L} 4 / 5$ & 1 & B & $\mathrm{L} 4 / 5 / \mathrm{S} 1$ & 3 & 3 \\
\hline 79 & $\mathrm{w}$ & $\mathrm{L} 4 / 5$ & 1 & B & $\mathrm{L} 4 / 5 / \mathrm{S} 1$ & 9 & 9 \\
\hline 83 & $\mathrm{w}$ & L5/S1 & 2 & $\mathrm{R}$ & $\mathrm{L} 4 / 5 / \mathrm{S} 1$ & - & 12 \\
\hline 70 & $\mathrm{w}$ & L5/S1 & 1 & $\mathrm{R}$ & $\mathrm{L} 4 / 5 / \mathrm{S} 1$ & 17 & 17 \\
\hline 80 & $\mathrm{~m}$ & $\mathrm{~L} 4 / 5$ & 1 & B & $\mathrm{L} 3 / 4 / 5$ & (1) & 10 \\
\hline 83 & $\mathrm{w}$ & $\mathrm{L} 4 / 5$ & 1 & $\mathrm{R}$ & $\mathrm{L} 3 / 4 / 5$ & 5 & 5 \\
\hline 73 & $\mathrm{w}$ & $\mathrm{L} 4 / 5$ & 2 & $\mathrm{R}$ & $\mathrm{L} 3 / 4 / 5 / \mathrm{S} 1$ & 8 & 9 \\
\hline 76 & $\mathrm{w}$ & $\mathrm{L} 4 / 5$ & 1 & B & $\mathrm{L} 4 / 5 / \mathrm{S} 1$ & 7 & 16 \\
\hline 65 & $\mathrm{~m}$ & $\mathrm{~L} 3 / 4$ & 1 & B & $\mathrm{L} 4 / 5 / \mathrm{S} 1$ & 7 & 7 \\
\hline 65 & $\mathrm{~m}$ & L5/S1 & 1 & B & $\mathrm{L} 4 / 5 / \mathrm{S} 1$ & - & 3 \\
\hline
\end{tabular}



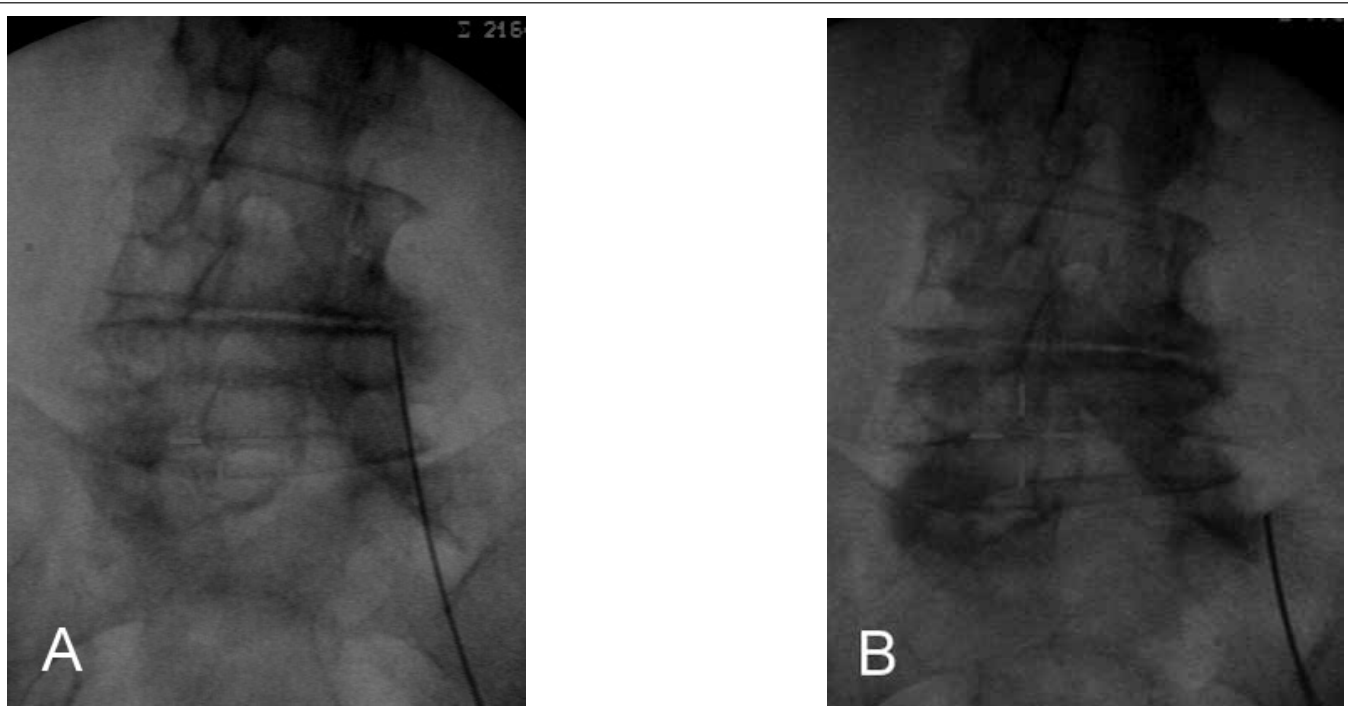

Fig. 2. Example of a radiofreqency neurotomy. A: Oblique radiograph. Position of the electrode beside the L5 superior articular process. B: Oblique radiograph of the same patient. Position of the electrode beside the S1 superior articular process.

Table 2. Results of different patient groups

\begin{tabular}{|c|c|c|c|}
\hline & \multirow{2}{*}{$\begin{array}{c}\text { All } \\
\text { patients }\end{array}$} & \multicolumn{2}{|c|}{ Response } \\
\hline & & positive & negative \\
\hline Number & 40 & $26(65.0 \%)$ & $14(35.0 \%)$ \\
\hline \multicolumn{4}{|l|}{ Age (years) } \\
\hline $40-49$ & 2 & 1 & 1 \\
\hline $50-59$ & 2 & 0 & 2 \\
\hline $60-69$ & 21 & 13 & 8 \\
\hline $70-79$ & 11 & 10 & 1 \\
\hline $80-89$ & 4 & 2 & 2 \\
\hline \multicolumn{4}{|l|}{ Gender } \\
\hline men & 14 & 8 & 6 \\
\hline women & 26 & 18 & 8 \\
\hline \multicolumn{4}{|l|}{ Level } \\
\hline $3 / 4$ & 5 & 5 & 0 \\
\hline $4 / 5$ & 19 & 10 & 9 \\
\hline $5 / 1$ & 16 & 11 & 5 \\
\hline \multicolumn{4}{|l|}{ Grade } \\
\hline I & 24 & 16 & 8 \\
\hline II & 16 & 10 & 6 \\
\hline \multicolumn{4}{|l|}{ RF-neurotomy } \\
\hline Left & 8 & 5 & 3 \\
\hline Right & 11 & 9 & 2 \\
\hline Both & 21 & 12 & 9 \\
\hline \multicolumn{4}{|c|}{ Follow up time (month) } \\
\hline mean & 18.6 & 18.0 & 19.6 \\
\hline Standard deviation & 13.9 & 13.8 & 14.7 \\
\hline
\end{tabular}

Seventy of these patients had degenerative spondylolisthesis, clearly demonstrated in MRI. These patients had no lumbar operation in their history and did not show any neurological deficits. Three patients were lost in follow-up; 27 had a follow-up of less than 3 months and were excluded. Therefore, 40 patients could be evaluated. Patient ages were between 41 and 83 years, the mean age being 67.8 years; $90 \%$ were older than 60 years. Fourteen men and 26 women were treated. The most frequent levels were L4/5 (19 cases) and L5/ S1 (16 cases). The affected level in 5 patients was L3/4. Most patients (24 cases) had minor spondylolisthesis (Meyerding grade 1 [17]) while 16 patients presented with a grade 2 spondylolisthesis. No patients with high grade (3 or 4) spondylolithesis were treated with radiofrequency neurotomy. Radiofrequency neurotomy was always performed only at the symptomatic side. The data are shown in Table 2.

A pain reduction of at least $50 \%$ and satisfying results for the patients in the radiofrequency group for a minimum of three months was achieved in 26 patients (65\%). Eight of these patients had a minimum of $50 \%$ pain relief; 18 had a minimum of $80 \%$. Eleven patients did not respond to radiofrequency neurotomy. In addition, 3 patients with a positive response to radiofrequency neurotomy but with pain relief lasting only one month were treated as negative successes. All patients with pain relief of 3 months had continuing pain relief at follow-up (Fig. 3). 


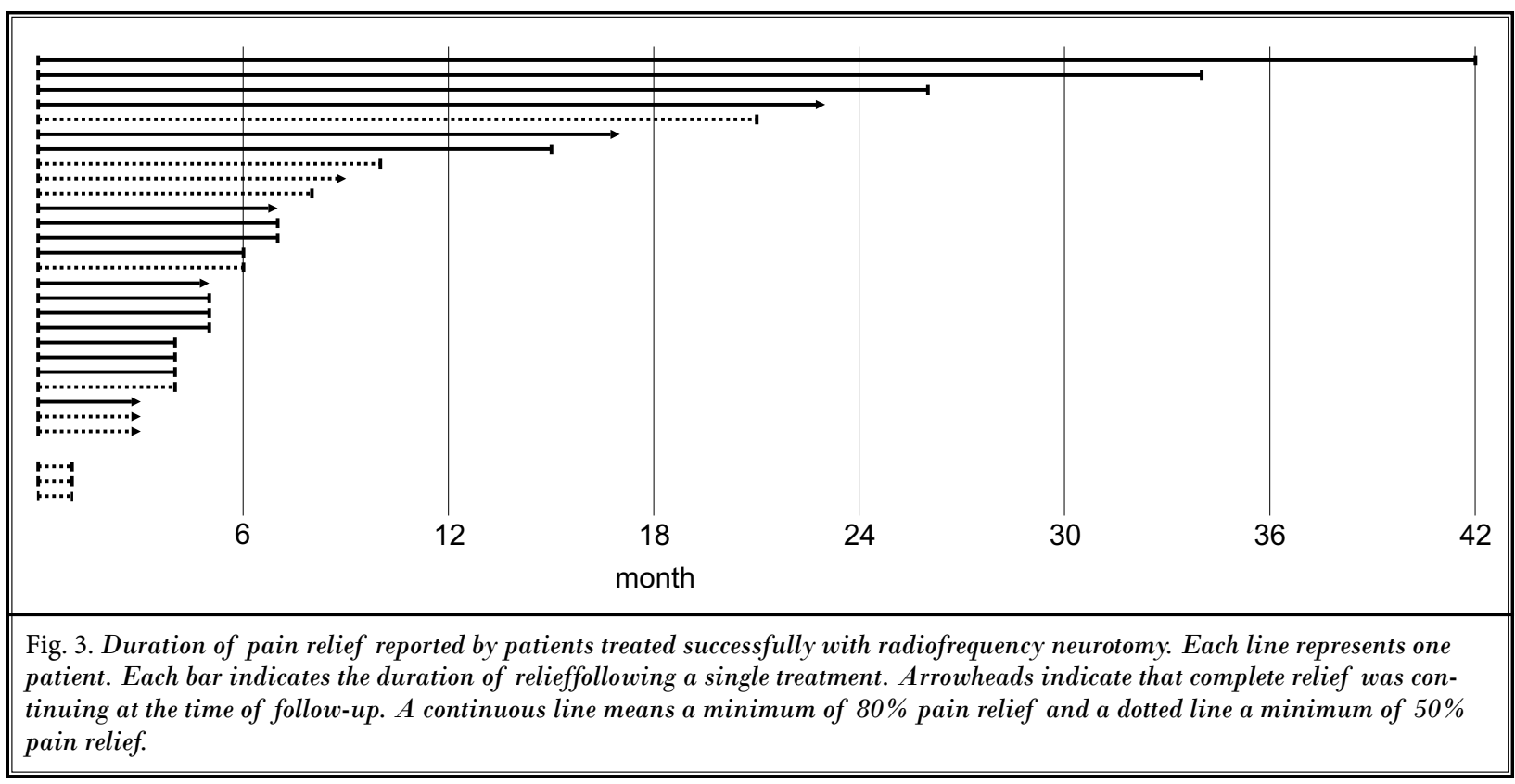

The mean duration of pain relief in the successfully treated patients was 10.9 months. The mean follow-up time of the 40 patients treated with radiofrequency neurotomy was 18.6 months (between 3 and 48 months, standard deviation [SD] 13.9). The range of the followup time was wide. However, $80 \%$ were followed up for a minimum of 6 months. The follow-up times in the successfully treated group (mean 18 months, SD 13.8) and in the nonresponsive group (mean 19.6 months, SD 14.7) are comparable. Details about the patients are shown in Tables 1 and 2.

There was no significant difference between these 2 groups in age, sex, grade of spondylolisthesis, and left side, right side or both sides treated. After radiofrequency neurotomy no adverse effects were encountered.

\section{Discussion}

This is the first study to determine if radiofrequency neurotomy is effective for patients with degenerative spondylolisthesis and low back pain. No other study was found testing the effect of radiofrequency neurotomy in these patients although this therapy method seems obvious, because morphological abnormalities of the lumbar zygapophysial joints are a predisposing factor in the development of degenerative spondylolisthesis (4), pathology of the zygapophysial joints is a significant cause of low back pain within the lumbar spine (3), and radiofrequency neurotomy is the "gold standard" for treating facetogenic pain (14).

There are various reasons for pain in patients with degenerative spondylolisthesis. One of the most probable sources for signs and symptoms related to degenerative spondylolisthesis are degenerated and subluxated zygapophysial joints and segmental instability that cause tension on the zygapophysial joint capsule and ligaments $(1,4)$. The instability of the spine as a consequence of zygapophysial joint pathology has been considered as a cause for degenerative spondylolisthesis for a long time $(3,18)$. Dai $(4)$ reports that patients with degenerative spondylolisthesis had more sagittally orientated zygapophysial joints $(P<0.01)$ and more significant zygapophysial joint tropism $(P<0.05)$ than normal control patients. Toyone et al (19) found that the cephalad portion of the facet joints are more sagittally oriented and the caudad portion of the facet joints are more coronally oriented in patients with degenerative spondylolisthesis. Often an increased joint volume indicates spinal instability (20), or synovial cysts can be found that are associated with degenerative spondylolisthesis and facet joint osteoarthritis (21). Exaggerated fluid in the facets seen on axial MRI is significantly suggestive of spondylolisthesis (22).

It is generally agreed that in most cases conservative treatment should be attempted before surgical intervention is pursued. Because of the absence of 
consensus guidelines from national or international organizations, the treatment of degenerative spondylolisthesis remains highly dependent on patient and physician expectations and preferences (1). Because of the important role the zygapophysial joints play, radiofrequency neurotomy is well justified. The specificity of radiofrequency neurotomy is an advantage because an important pain source is targeted, but it is also a disadvantage because only this single pain generator can be addressed. The selection criteria for medial branch blocks $(80 \%)$ and for a positive treatment response (50\% pain relief for a minimum of 3 months) are in accordance with recent multicenter studies of radiofrequency neurotomy (23).

Despite the above-mentioned restrictions, this study shows that radiofrequency neurotomy may be a useful, effective, and rational therapy for patients with low back pain due to degenerative spondylolisthesis. Sufficient pain reduction was achieved in $65 \%$ of the treated patients for a reasonable time. To compare the success rate with the literature is impossible, because this study is the first available study. There are no data on the effectiveness of lumbar radiofrequency neurotomy for patients with a degenerative spondylolisthesis. It would be helpful to compare the results of patients with spondylolisthesis to those without spondylolisthesis. Unfortunately, there is no study about the effectiveness of medial branch neurotomy in patients with back pain explicitly excluding patients with spondylolisthesis.

Manchikanti et al (7) found strong evidence that radiofrequency denervation offers short-term a swell as long-term relief for pain of zygapophysial joint origin. A correct placement of the cannula may improve the results of radiofrequency denervation (16). The efficacy of radiofrequency neurotomy was reviewed by Bogduk et al in 2009 (9). The first clinical study that used appropriate selection criteria and that used correct surgical techniques was a descriptive study (10). In that study, $60 \%$ of patients sustained at least $80 \%$ pain relief lasting at least 12 months; $80 \%$ sustained at least $60 \%$ relief. Similar outcomes were corroborated by another descriptive study by Gofeld et al (11). They found that $68 \%$ of the patients maintained at least $50 \%$ pain relief for 6 to 24 months. A third study showed that medial branch neurotomy achieved significant pain reductions (12). In our study, patients were highly selected; only patients with degenerative spondylolisthesis were included. Nevertheless, even under these conditions, 65\% of patients treated obtained satisfying relief.

It is known that these patients might have sources of pain other than just the zygapophysial joints (24). In particular, spinal canal stenosis is often present, which causes symptoms not treated by medial branch neurotomy. Spinal canal stenosis is often symptomatic with neurogenic claudication and radiculopathy. In addition, back pain is common. The second pathology which is often interlinked with degenerative spondylolisthesis is disc degeneration $(1,2)$. Discogenic pain is also not treated by medial branch neurotomy.

Our patient selection is comparable to other studies. The age of the patients (typically older than 40 years [1]), the usually mild degree of slip $(25,26)$, the levels involved $(6,18,27,28)$, and the more frequent occurrence in women (28-30) are typical. Patients with neurological deficits were excluded because a progressive deficit might be an indication for surgical therapy (31). In addition, a history of a lumbar operation was a reason for exclusion of the patient because postsurgical spondylolisthesis is a different type of spondylolisthesis.

There are limitations of this study. It was a retrospective practice audit. The outcome was qualitative rather than quantitative. The main problem is the widespread follow-up time. Unfortunately, some patients did not attend their subsequent follow-up. We do not know if they did not come again because they were satisfied with the result or if their relief lapsed. This audit is retrospective and observational, and therefore does not represent a high level of evidence.

\section{Conclusion}

Since no specific nonoperative treatment for lumbar pain in patients with minor degenerative spondylolisthesis exists, it appears to be the best available research upon which to recommend treatment and to plan higher quality studies. Further studies are needed to investigate the possibility of applying radiofrequency neurotomy to complex situations like degenerative spondylolisthesis. 


\section{References}

1. Kalichman L, Hunter DJ. Diagnosis and conservative management of degenerative lumbar spondylolisthesis. Eur Spine ] 2008; 17:327-335.

2. Sengupta DK, Herkowitz HN. Degenerative spondylolisthesis: Review of current trends and controversies. Spine (Phila Pa 1976) 2005; 30:S71-81.

3. Berven S, Tay BB, Colman W, Hu SS. The lumbar zygapophyseal (facet) joints: A role in the pathogenesis of spinal pain syndromes and degenerative spondylolisthesis. Semin Neurol 2002; 22:187-196.

4. Dai LY. Orientation and tropism of lumbar facet joints in degenerative spondylolisthesis. Int Orthop 2001; 25:40-42.

5. Vibert BT, Sliva CD, Herkowitz HN. Treatment of instability and spondylolisthesis: Surgical versus nonsurgical treatment. Clin Orthop Relat Res 2006; 443:222-227.

6. Frymoyer JW. Degenerative spondylolisthesis: Diagnosis and treatment. J Am Acad Orthop Surg 1994; 2:9-15.

7. Manchikanti L, Singh V, Vilims BD, Hansen HC, Schultz DM, Kloth DS. Medial branch neurotomy in management of chronic spinal pain: Systematic review of the evidence. Pain Physician 2002; 5:405418.

8. International Spine Intervention Society. Percutaneous radiofrequency lumbar medial branch neurotomy. In: Bogduk N, (ed). Practice Guidelines for Spinal Diagnostic and Treatment Procedures. International Spine Intervention Society, San Francisco, 2004, pp 188-218.

9. Bogduk N, Dreyfuss P, Govind J. A narrative review of lumbar medial branch neurotomy for the treatment of back pain. Pain Med 2009; 10:1035-1045.

10. Dreyfuss P, Halbrook B, Pauza K, Joshi A, McLarty J, Bogduk N. Efficacy and validity of radiofrequency neurotomy for chronic lumbar zygapophysial joint pain. Spine (Phila Pa 1976) 2000; 25:1270-1277.

11. Gofeld M, Jitendra J, Faclier G. Radiofrequency denervation of the lumbar zygapophysial joints: 10-year prospective clinical audit. Pain Physician 2007; 10:291-300.

12. Burnham RS, Holitski S, Dinu I. A pro- spective outcome study on the effects of facet joint radiofrequency denervation on pain, analgesic intake, disability, satisfaction, cost, and employment. Arch Phys Med Rehabil 2009; 90:201-205.

13. Boswell MV, Colson JD, Sehgal N, Dunbar EE, Epter R. A systematic review of therapeutic facet joint interventions in chronic spinal pain. Pain Physician 2007; 10:229-253.

14. Van Kleef M, Vanelderen P, Cohen SP, Lataster A, Van Zundert J, Mekhail N. 12. Pain originating from the lumbar facet joints. Pain Pract 2010; 10:459-469.

15. International Spine Intervention Society. Lumbar medial branch blocks. In: Bogduk N, (ed). Practice Guidelines for Spinal Diagnostic and Treatment Procedures. International Spine Intervention Society, San Francisco, 2004, pp 47-65.

16. Gofeld M, Faclier G. Radiofrequency denervation of the lumbar zygapophysial joints--targeting the best practice. Pain Med 2008; 9:204-211.

17. Meyerding HW. Spondyloptosis. Surg Gynaecol Obstet 1932; 54:371-377.

18. Fitzgerald JA, Newman PH. Degenerative spondylolisthesis. J Bone Joint Surg $\mathrm{Br}$ 1976; 58:184-192.

19. Toyone T, Ozawa T, Kamikawa K, Watanabe A, Matsuki K, Yamashita T, Wada $Y$. Facet joint orientation difference between cephalad and caudad portions: A possible cause of degenerative spondylolisthesis. Spine (Phila Pa 1976) 2009; 34:2259-2262.

20. Hasegawa K, Kitahara K, Shimoda H, Hara T. Facet joint opening in lumbar degenerative diseases indicating segmental instability. J Neurosurg Spine 2010; 12:687-693.

21. Alicioglu B, Sut N. Synovial cysts of the lumbar facet joints: A retrospective magnetic resonance imaging study investigating their relation with degenerative spondylolisthesis. Prague Med Rep 2010; 110:301-309.

22. Schinnerer KA, Katz LD, Grauer JN. MR findings of exaggerated fluid in facet joints predicts instability. J Spinal Disord Tech 2008; 21:468-472.

. Cohen SP, Williams KA, Kurihara C,
Nguyen C, Shields C, Kim P, Griffith SR, Larkin TM, Crooks M, Williams N, Morlando B, Strassels SA. Multicenter, randomized, comparative cost-effectiveness study comparing 0,1 , and 2 diagnostic medial branch (facet joint nerve) block treatment paradigms before lumbar facet radiofrequency denervation. Anesthesiology 2010; 113:395-405.

24. Jensen TS, Karppinen J, Sorensen JS, Niinimäki J, Leboeuf-Yde C. Vertebral endplate signal changes (Modic change): A systematic literature review of prevalence and association with non-specific low back pain. Eur Spine J 2008;17(11):1407-1422.

25. Rosenberg NJ. Degenerative spondylolisthesis. Predisposing factors. J Bone Joint Surg Am 1975; 57:467-474.

26. Denard PJ, Holton KF, Miller J, Fink HA, Kado DM, Yoo JU, Marshall LM; Osteoporotic Fractures in Men (MrOS) Study Group. Lumbar spondylolisthesis among elderly men: Prevalence, correlates, and progression. Spine (Phila $\mathrm{Pa}$ 1976) 2010; 35:1072-1078.

27. Aihara T, Takahashi K, Yamagata $M$, Moriya H, Tamaki T. Biomechanical functions of the iliolumbar ligament in L5 spondylolysis. J Orthop Sci 2000; 5:238-242.

28. Jacobsen $S$, Sonne-Holm S, Rovsing H, Monrad H, Gebuhr P. Degenerative lumbar spondylolisthesis: An epidemiological perspective: The Copenhagen Osteoarthritis Study. Spine (Phila Pa 1976) 2007; 32:120-125.

29. Pearson A, Blood E, Lurie J, Tosteson $\mathrm{T}$, Abdu WA, Hillibrand A, Bridwell K, Weinstein J. Degenerative spondylolisthesis versus spinal stenosis: Does a slip matter? Comparison of baseline characteristics and outcomes (SPORT). Spine (Phila Pa 1976) 2010; 35:298-305.

30. Kalpakcioglu B, Altinbilek T, Senel K. Determination of spondylolisthesis in low back pain by clinical evaluation. J Back Musculoskelet Rehabil 2009; 22:2732.

31. Herkowitz HN. Spine update. Degenerative lumbar spondylolisthesis. Spine (Phila Pa 1976) 1995; 20:1084-1090. 